\section{Respostas da percepção subjetiva de esforço em teste incremental de mulheres idosas sedentárias}

\section{Ratings of perceived exertion in an incremental test in elderly women}

\author{
Denis César Leite Vieira ${ }^{1}$ \\ Bibiano Madrid ${ }^{1}$ \\ Flávio de Oliveira Pires ${ }^{1,2}$ \\ Vitor Tajra ${ }^{1}$, \\ Darlan Lopes de Farias ${ }^{1,3}$ \\ Tatiane Gomes Teixeira \\ Ramires Alsamir Tibana ${ }^{1}$ \\ Jonato Prestes ${ }^{1}$
}

Resumo - Apesar da percepção subjetiva de esforço (PSE) ser utilizada para a avaliação e prescrição de exercícios em idosos, alguns indivíduos podem apresentar dificuldades de entendimento a escala de Borg. Nesse sentido, o objetivo do estudo foi verificar se mulheres idosas percebem, associam e relatam alterações no esforço físico por meio da PSE, em resposta a um teste de esforço máximo, bem como se é possível predizer o ponto de compensação respiratória (PCR) pela escala de Borg. Vinte e seis mulheres idosas realizaram uma avaliação de esforço máximo em esteira com análise ergoespirométrica, eletrocardiográfica e PSE em protocolo de rampa. As respostas de PSE entre diferentes zonas de intensidade baixa, moderada e alta foram consideradas para avaliar a percepção, associação e relato de alterações no esforço. Oito voluntárias (30,77\%) não perceberam, associaram e relataram alterações no esforço por meio da PSE. Naquelas que perceberam, associaram e relataram alterações no esforço, o percentual da potência máxima no momento da PSE $13(69,92 \pm 10,30)$ e $14(78,90 \pm 11,00)$ não diferiu significativamente do momento do PCR $(75,45 \pm 9,65)$. Por fim, conclui-se que mulheres idosas podem apresentar dificuldades em perceber, associar e relatar alterações no esforço por meio da escala de Borg. Contudo, naquelas que percebem, associam e relatam alterações no esforço por meio da escala de Borg, as PSE 13 e 14 coincidem com o PCR.

Palavras-chave: Envelhecimento; Esforço físico; Teste de esforço.

Abstract - Although the rating of perceived exertion (RPE) is used in the evaluation and prescription of physical activity for the elderly, some subjects might find it hard tounderstand the Borg scale. This study aimed to verify whether elderly women could notice, associate, and report changes in physical effort using the perceived exertion scale in response to a stress test. We also aimed to verify the possibility of predicting a respiratory compensation point (RCP) using the Borg scale. Twenty six elderly women took a stress test on a treadmill, with ergospirometry and ECG monitoring and RPE in a ramp protocol. Based on the RPEs for different exercise intensities (low, moderate, high), we assessed the women's perception, association, and report of changes in physical effort. Eight subjects (30.77\%) did not notice, associate or report changes in effort using RPE. For those who did, the percentage of maximum workload at the moment of RPE $13(69.92 \pm 10,30)$ and $14(78.90 \pm 11,00)$ did not differ significantly from the one at the moment of RCP (75.45 \pm 9.65$)$. We conclude that some elderly women may have difficulties noticing, associating and reporting changes in physical effort using the Borg scale. However, for those who do not have any difficulty, RPE 13 and 14 coincide with the RCP.

Key words: Aging; Exercise test; Physical exertion.
1 Universidade Católica de Brasília. Programa de Pós-Graduação em Educação Física. Aguas Claras, DF. Brasil.

2 Universidade de São Paulo. Escola de Artes, Ciências e Humanidades. São Paulo, SP. Brasil

3 Centro Universitário de Brasília. Faculdade de Ciências da Saúde - Graduação em Educação Física. Brasília, DF. Brasil

Recebido em 19/12/12 Revisado em 26/05/13 Aprovado em 24/06/13 


\section{INTRODUÇÃO}

A prática de exercícios físicos auxilia na promoção da saúde, envelhecimento saudável, na redução do risco de doenças crônicas e limitações funcionais em idosos ${ }^{1-3}$. No entanto, para a segurança e sucesso de um programa de exercício físico se faz necessária uma avaliação cardiorrespiratória. Nesse sentido, o teste de esforço (TE) com mensuração do consumo de oxigênio $\left(\mathrm{VO}_{2}\right)$ e monitoramento de sinais eletrocardiográficos é comumente utilizado para avaliação cardiorrespiratória, visando à detecção precoce de eventuais anormalidades cardíacas, bem como para verificação dos efeitos de um programa de treinamento sobre o condicionamento físico ${ }^{2,4}$. Durante um TE, algumas variáveis como frequência cardíaca (FC), $\mathrm{VO}_{2}$ e pressão arterial (PA) são rotineiramente utilizadas para a identificação das respostas fisiológicas geradas pelo esforço $\mathrm{O}^{2,4,5}$.

Outra variável normalmente obtida durante a execução de um TE é a percepção subjetiva de esforço (PSE). Sugere-se a PSE como uma variável psicofisiológica, resultante das informações aferentes oriundas de alterações nos músculos cardíaco, respiratório e esquelético, além da ativação cortical durante o exercício ${ }^{6,7}$. Estes prováveis mecanismos apoiam a proposta de que a PSE possa ser utilizada para predizer a carga interna de treinamento ${ }^{8}$, além de demarcar a intensidade ${ }^{6,9}$ e duração de exercício ${ }^{10}$. De fato, a PSE tem sido utilizada em associação à identificação de marcadores de domínios fisiológicos, tais como o limiar anaeróbio (LAn) ${ }^{2,11,12}$.

Por sua simplicidade, baixo custo e efetividade em determinar a intensidade de exercício, a PSE pode ser uma importante ferramenta na aplicação de avaliações funcionais. Contudo, sua aplicabilidade tem sido questionada em populações específicas. Por exemplo, Simões et al. ${ }^{11}$ notaram que alguns indivíduos diabéticos tipo 2 podem apresentar respostas de PSE não proporcionais ao estresse fisiológico a que eram submetidos em TE. Especula-se que esses resultados poderiam estar ligados ao processo de envelhecimento, pois com o avanço da idade há uma redução do fluxo sanguíneo cerebral durante o exercício ${ }^{13}$, o que pode levar a declínios em funções cognitivas, refletindo na capacidade do idoso em responder ao esforço de forma adequada ${ }^{14}$.

Sendo assim, o presente estudo teve como objetivo analisar se mulheres idosas percebem, associam e relatam alterações no esforço físico pela escala de Borg em resposta a um TE. Ademais, um segundo objetivo foi verificar quais respostas de PSE coincidem com as intensidades referentes ao LAn e ao ponto de compensação respiratória (PCR).

\section{PROCEDIMENTOS METODOLÓGICOS}

\section{Indivíduos}

O estudo foi aprovado no Comitê de Ética para Pesquisa em Seres Humanos da Universidade Católica de Brasília (resolução 196/96 do Conselho Nacional de Saúde) (PROJETO N²35/2010). A amostra foi selecionada 
por conveniência e após assinarem o Termo de Consentimento Livre e Esclarecido, participaram desse estudo, de forma voluntária, 28 mulheres. Contudo, duas mulheres foram excluídas da análise por não atingirem os critérios adotados para evidenciar o esforço máximo durante a avaliação. As características descritivas da amostra estão presentes na tabela 1. Os critérios de inclusão do estudo foram: mulheres com idade $\geq 60$ anos e não ter participado de nenhum programa de exercício físico sistematizado nos seis meses anteriores ao estudo. Enquanto que, os critérios de exclusão foram: presença de doenças cardiorrespiratórias, limitações físicas que comprometessem a saúde e desempenho durante os testes e utilização de medicamentos betabloqueadores adrenérgicos.

Tabela 1. Dados antropométricos e de aptidão cardiorrespiratória da amostra participante do estudo.

\begin{tabular}{cccccc}
\hline $\begin{array}{c}\text { Idade } \\
\text { (anos) }\end{array}$ & $\begin{array}{c}\text { Peso } \\
(\mathrm{kg})\end{array}$ & $\begin{array}{c}\text { Estatura } \\
(\mathrm{cm})\end{array}$ & $\begin{array}{c}\mathrm{IMC} \\
\left(\mathrm{kg} / \mathrm{m}^{2}\right)\end{array}$ & $\begin{array}{c}\mathrm{VO}_{2 \text { ico }} \\
\left(\mathrm{mL} \cdot \mathrm{kg} \cdot \mathrm{min}^{-1}\right)\end{array}$ \\
\hline $\mathrm{n}=26$ & $67,8 \pm 6,7$ & $65,7 \pm 10,0$ & $155,2 \pm 8,1$ & $27,2 \pm 4,1$ & $21,5 \pm 2,9$ \\
\hline
\end{tabular}

IMC = Índice de massa corporal; V02pico = Consumo de oxigênio pico.

\section{Procedimentos gerais}

As voluntárias selecionadas realizaram TE em esteira rolante (Imbramed Super ATL - Brasil) com análise ergoespirométrica (Cortex Metalyzer 3B - Metasoft, Alemanha) e eletrocardiográfica (Micromed ${ }^{\bullet}$ - Ergo PC, Brasil) em uma sala com temperatura, pressão barométrica e umidade relativa do ar controlada no Laboratório de avaliação física e treinamento da Universidade Católica de Brasília, na presença de um médico, para identificar possíveis anormalidades cardíacas durante o exercício. Durante a avaliação, foram mensuradas continuamente a frequência cardíaca, o consumo de oxigênio, pressão arterial e a percepção subjetiva de esforço.

\section{Teste de esforço (TE)}

O TE foi realizado para identificação do LAn, PCR e consumo de oxigênio pico $\left(\mathrm{VO}_{2 \text { pico }}\right)$. O protocolo de avaliação utilizado foi o de rampa, com incrementos de velocidade (entre 0,004 a $0,005 \mathrm{Km} / \mathrm{h}$ a cada segundo) e principalmente, inclinação (entre 0,015 a $0,021 \%$ a cada segundo), ajustados para garantir o alcance da exaustão voluntária entre oito e doze minutos $^{15}$. O protocolo foi ajustado com maiores incrementos de inclinação em relação à velocidade, evitando que as voluntárias tivessem que correr e pudessem interromper o teste antes do alcance de valores máximos, devido a limitações de locomoção. O teste, finalizado na exaustão voluntária, foi assumido como máximo de acordo com os seguintes critérios: FC acima de $85 \%$ da FC máxima prevista (220 - idade) e razão de troca respiratória $(\mathrm{R})$ $>1,0^{2}$. Ademais, o tempo total do teste foi normalizado em porcentagens, respeitando intervalos de $10 \%{ }^{16}$.

\section{Análise ventilatórias}

Foram mensurados os gases expirados de forma contínua, respiração a 
respiração (Cortex Metalyzre 3B - Metasoft, Alemanha). A calibração dos equipamentos de análise gasosa era realizada antes de cada teste de acordo com recomendações do fabricante. Os dados de trocas gasosas foram convertidos para médias de vinte segundos (20x20), para análise da ventilação (VE), consumo de oxigênio $\left(\mathrm{VO}_{2}\right)$, produção de dióxido de carbono $\left(\mathrm{VCO}_{2}\right)$, equivalente ventilatório de oxigênio $\left(\mathrm{VE} / \mathrm{VO}_{2}\right)$, equivalente ventilatório de dióxido de carbono $\left(\mathrm{VE} / \mathrm{VCO}_{2}\right)$, para a identificação do LAn e PCR por dois pesquisadores independentes. O LAnfoi identificado pelo aumento da razão $\mathrm{VE} / \mathrm{VO}_{2}$ sem aumento da razão $\mathrm{VE} / \mathrm{VCO}_{2}{ }^{17,18}$. Enquanto que o PCR foi identificado considerando um aumento abrupto da razão $\mathrm{VE} / \mathrm{VCO}_{2}{ }^{18}$. Dada as dificuldades em encontrar platô na curva do $\mathrm{VO}_{2}$ nessa população ${ }^{2}$, foi assumido $\mathrm{VO}_{2 \text { pico }}$ no maior $\mathrm{VO}_{2}$ obtido antes do término do exercício ${ }^{19}$. Para quantificar a intensidade do exercício, foram determinadas três zonas de intensidade, denominadas: baixa intensidade, moderada intensidade e alta intensidade ${ }^{20}$.

\section{Percepção subjetiva de esforço (PSE)}

Antes da avaliação, as voluntárias foram submetidas aos seguintes procedimentos em relação à escala de $\mathrm{BORG}^{6}$ : foram apresentadas a cada item da escala de Borg (6-20) e receberam a instrução que por meio daquela escala iriam relatar a sensação de tensão, esforço e fadiga ao qual estavam sendo submetidas durante o teste, tanto em nível cardiorrespiratório, quanto muscular, ou seja, PSE geral. Adicionalmente, durante a avaliação, ao início de cada minuto, os indivíduos foram orientados a indicar a sensação de esforço por meio da escala de Borg. As respostas de PSE foram analisadas em função do tempo total do teste ${ }^{21}$. Para determinar que o indivíduo percebeu, associou e relatou alterações no esforço, foram consideradas as respostas de percepção de esforço de três diferentes zonas de intensidade: baixa intensidade (BI), correspondente a resposta de percepção de esforço a 50\% do tempo entre o início do teste e o LAn, moderada intensidade (MI), correspondente a resposta de percepção de esforço a 50\% do tempo entre o LAn e PCR, e alta intensidade (AI), correspondente a resposta de percepção subjetiva de esforço a $25 \%$ do tempo entre o PCR e o fim do teste ${ }^{20}$. Nesse sentido, em caso de igualdade ou decréscimo das respostas de percepção de esforço entre as zonas de intensidades anteriores, foi considerado que o indivíduo não percebeu, associou e relatou alterações no esforço de forma adequada.

Predição do ponto de compensação respiratória e do LAn por meio da PSE Para verificar a associação entre LAn, PCR e a PSE, os valores percentuais da potência máxima ( $\mathrm{POT}_{\max }$ ) correspondente às PSE 10 (P10), PSE 11 (P11), PSE 12 (P12), PSE 13 (P13), PSE 14 (P14) e PSE 15 (P15) foram obtidos por meio de uma regressão linear entre POT $_{\text {max }}$ e PSE de cada indivíduo em cada percentual do tempo de exaustão e comparados ao momento do PCR (PPCR) e ao LAn (PLAn). Ademais o percentual do $\mathrm{VO}_{2 \text { ico }}$ e da frequência cardíaca máxima $\left(\mathrm{FC}_{\max }\right)$, também foram estabelecidos e comparados nesses momentos ${ }^{11}$. 


\section{Análise estatística}

Para análise dos dados, foi utilizada estatística descritiva com média e desvio padrão. A normalidade dos dados foi verificada por meio do teste de Shapiro-Wilk. A correlação entre PSE com o percentual da frequência cardíaca máxima e o percentual do $\mathrm{VO}_{2 \text { ico }}$ mensuradas a cada percentual do tempo de exaustão foram determinadas pela correlação de Pearson. Utilizaram-se a ANOVA de medidas repetidas com correção da esfericidade de Greenhouse e Geisser e o post-hoc de Tukey para comparar os percentuais da $\mathrm{POT}_{\text {max }}, \mathrm{VO}_{\text {2pico }}$ e $\mathrm{FC}_{\max }$ nos momentos P12, P13, P14 e P15 com o momento PPCR e os percentuais da POT $\mathrm{P}_{\max }, \mathrm{VO}_{\text {2pico }}$ e $\mathrm{FC}_{\max }$ dos momentos P10, P11, P12 e P13 com o momento do PLAn. Os dados foram analisados através do programa Statistical Package for the Social Sciences - SPSS (v.19, Chicago, IL). O nível de significância adotado foi de $\mathrm{p}<0,05$.

\section{RESULTADOS}

As médias de frequência cardíaca máxima, percentual da frequência cardíaca máxima prevista, consumo de oxigênio pico e razão de troca gasosa da amostra foram $148,00 \mathrm{bpm}( \pm 32,6), 100,91 \%( \pm 7,34), 21,5 \mathrm{~mL} \cdot \mathrm{kg} \cdot \mathrm{min}^{-1}( \pm$ $2,9)$ e $1,11( \pm 0,06)$, respectivamente. Das vinte e seis mulheres incluídas na análise, oito $(30,77 \%)$ não perceberam, associaram e relataram alterações no esforço em diferentes zonas de intensidades (NPARE). As médias de PSE, percentual do $\mathrm{VO}_{2 \text { pico }}$ e percentual da frequência cardíaca máxima $\left(\mathrm{FC}_{\max }\right)$ aumentaram a cada percentual de tempo de exaustão à medida que se aproximavam da exaustão (Tabela 2) nos indivíduos que perceberam, associaram e relataram no esforço em diferentes zonas de intensidades (PARE), segundo os critérios adotados. Ademais, altas correlações foram encontradas entre PSE com o percentual da $\mathrm{FC}_{\max }(\mathrm{r}=0,991 ; \mathrm{p}<0,05)$ e PSE com percentual do $\mathrm{VO}_{2 \text { pico }}(\mathrm{r}=0,958 ; \mathrm{p}<0,05)$.

Tabela 2. Média e desvio padrão do consumo de oxigênio, frequência cardíaca e PSE a cada percentual do tempo de exaustão nas mulheres que perceberam, associaram e relataram o esforço de forma adequada $(n=18)$.

\begin{tabular}{lccccccccc}
\hline & $20 \%$ & $30 \%$ & $40 \%$ & $50 \%$ & $60 \%$ & $70 \%$ & $80 \%$ & $90 \%$ & $100 \%$ \\
\hline PSE & $8,1 \pm 1,0$ & $8,9 \pm 1,3$ & $9,9 \pm 1,4$ & $10,9 \pm 1,9$ & $11,4 \pm 1,8$ & $12,3 \pm 1,9$ & $13,4 \pm 1,8$ & $15,2 \pm 1,7$ & $17,2 \pm 1,4$ \\
$\% \mathrm{VO}_{2 \text { pico }}$ & $52,5 \pm 8,6$ & $60,1 \pm 9,9$ & $67,1 \pm 9,7$ & $74,3 \pm 5,9$ & $79,1 \pm 5,4$ & $85,9 \pm 5,5$ & $90,8 \pm 4,4$ & $96,1 \pm 2,7$ & $100 \pm 0,0$ \\
$\% \mathrm{FC}_{\max }$ & $60,0 \pm 6,5$ & $70,2 \pm 6,9$ & $74,4 \pm 5,6$ & $77,8 \pm 5,1$ & $81,5 \pm 4,4$ & $86,5 \pm 4,1$ & $90,9 \pm 3,8$ & $95,5 \pm 2,7$ & $100 \pm 0,0$ \\
\hline
\end{tabular}

PSE = percepção subjetiva de esforço; V02pico = consumo de oxigênio pico; $\mathrm{FCmax}=$ frequência cardíaca máxima

O percentual da $\mathrm{POT}_{\max }$ não apresentou diferença significante $(\mathrm{F}[1,16$; 19,67] = 47,01; $\mathrm{p}<0,05)$ entre o momento P10 $(42,96 \pm 10,24)$ e PLAn $(43,08$ $\pm 11,70)$. Já o percentual da $\mathrm{POT}_{\max }$ dos momentos P11 (51,95 $\left.\pm 9,90\right)$, P12 $(60,93 \pm 9,92)$ e $\mathrm{P} 13(69,92 \pm 10,30)$ foram maiores quando comparado ao PLAn $(43,08 \pm 11,70)$. Ademais, o percentual da $\mathrm{FC}_{\max }$ foi menor (F $[1,51$; 26,63] = 48,05; $\mathrm{p}<0,05)$ no PLAn quando comparado ao P11, P12 e P13. Para o percentual do $\mathrm{VO}_{\text {2pico, }}$ apenas os momentos $\mathrm{P} 12$ e P13 apresentaram diferença significante $(\mathrm{F}[1,14 ; 19,44]=33,13 ; \mathrm{p}<0,05)$ quando comparado ao PLAn, conforme apresentado na tabela 3. 
Tabela 3. Comparação entre os momentos P10, P11, P12 e P13 com PLAn daquelas que perceberam, associaram e relataram 0 esforço de forma adequada $(n=18)$.

\begin{tabular}{|c|c|c|c|c|c|}
\hline & PLAn & P10 & P11 & P12 & P13 \\
\hline$\% \mathrm{POT}_{\max }$ & $43,08 \pm 11,70$ & $42,96 \pm 10,24$ & $51,95 \pm 9,90^{*}$ & $60,93 \pm 9,92^{*}$ & $69,92 \pm 10,30 *$ \\
\hline$\% \mathrm{VO}_{2 \text { pico }}$ & $74,04 \pm 9,24$ & $69,93 \pm 7,79$ & $75,60 \pm 7,37$ & $81,28 \pm 7,19^{*}$ & $86,95 \pm 7,23^{*}$ \\
\hline$\% \mathrm{FC}_{\max }$ & $77,65 \pm 7,13$ & $77,43 \pm 7,30$ & $81,07 \pm 4,13^{*}$ & $84,72 \pm 5,50^{*}$ & $88,37 \pm 4,85^{*}$ \\
\hline
\end{tabular}

\%POTmax = percentual da potência máxima; \% V02Pico = percentual do consumo de oxigênio pico; \%FCmax $=$ percentual da frequência cardíaca máxima; $P L A n=$ Momento referente ao limiar anaeróbio; P10 = Momento referente a PSE 10; P11 = momento referente a PSE 11; P12 = momento referente a PSE 12; P13 = momento referente a PSE 13; $\left(^{*}\right)$ Diferença significativa em comparação a PLAn $(p<0,05)$.

Em relação ao PCR, o percentual da $\mathrm{POT}_{\max }$ apresentou diferença significante $(\mathrm{F}[1,13 ; 19,24]=27,89 ; \mathrm{p}<0,05)$, entre os momentos P12 $(60,93$ $\pm 9,92 \%)$ e P15 $(87,89 \pm 11,97 \%)$ comparado a PPCR (75,45 $\pm 9,65 \%)$. No entanto, P13 (69,92 \pm 10,30\%) e P14 (78,90 \pm 11,00\%) não foram significativamente diferentes quando comparados ao $\operatorname{PPCR}(75,45 \pm 9,65 \%)$. Ademais, os valores dos percentuais da $\mathrm{FC}_{\text {max }}(\mathrm{F}[1,38 ; 23,42]=24,37 ; \mathrm{P}<0,05)$ nos momentos P12 e P15, também apresentaram diferença significativa comparado ao momento PPCR. Para os percentuais do $\mathrm{VO}_{\text {2pico }}$, somente $\mathrm{P} 14$ não apresentou diferença significante $(\mathrm{F}[1,20 ; 20,42]=36,25 ; \mathrm{P}<0,05)$ quando comparado ao PPCR (Tabela 4).

A média da PSE relatada no momento do esforço máximo foi de 17,2 $( \pm 1,4)$ e somente $27,78 \%$ do grupo PARE apresentou PSE maior do que 17 no momento do esforço máximo.

Tabela 4. Comparação entre os momentos P12, P13, P14 e P15 com PPCR daquelas que perceberam, associaram e relataram 0 esforço de forma adequada $(n=18)$.

\begin{tabular}{lccccc}
\hline & PPCR & P12 & P13 & P14 & P15 \\
\hline$\% \mathrm{PO}_{\text {Tma }} \mathrm{x}$ & $75,45 \pm 9,65$ & $60,93 \pm 9,92^{*}$ & $69,92 \pm 10,30$ & $78,90 \pm 11,00$ & $87,89 \pm 11,97^{*}$ \\
$\% \mathrm{VO}_{2 \text { pico }}$ & $91,92 \pm 4,24$ & $81,28 \pm 7,19^{*}$ & $86,95 \pm 7,23^{*}$ & $92,62 \pm 7,51$ & $98,30 \pm 8,00^{*}$ \\
$\% \mathrm{FC}_{\max }$ & $90,32 \pm 5,14$ & $84,72 \pm 5,50^{*}$ & $88,37 \pm 4,85$ & $92,01 \pm 4,48$ & $95,65 \pm 4,47^{*}$ \\
\hline
\end{tabular}

$\% \mathrm{POT}_{\max }=$ percentual da potência máxima; $\% \mathrm{VO}_{\text {2Pico }}=$ percentual do consumo de oxigênio pico; $\% \mathrm{FC}_{\max }=$ percentual da frequência cardíaca máxima; $P P C R=$ 2Pico $=$ momento referente ao ponto de compensação respiratória.; P12 = momento referente a PSE 12; P13 = momento referente a PSE 13; P14 = momento referente a PSE 14; P15 $=$ momento referente a PSE $\left.15 ;{ }^{*}\right)$ Diferença significativa em comparação a $\operatorname{PPCR}(p<0,05)$.

\section{DISCUSSÃO}

O objetivo do presente estudo foi analisar se mulheres idosas percebem, associam e relatam alterações no esforço físico pela PSE em resposta a um TE, bem como, verificar com qual resposta de PSE coincide o PCR e o LAn. Confirmando nossa hipótese inicial, os resultados do presente estudo demonstram que $30,77 \%$ da amostra apresentaram dificuldades de percepção, associação e relato de alterações no esforço por meio da escala de Borg durante um TE com o protocolo de rampa. No entanto, vale ressaltar que, no presente estudo, a maior parte da amostra $(69,23 \%)$ percebeu, associou e relatou alterações no esforço de acordo com os critérios adotados.

Em diabéticos tipo 2, com idade média de 53,4 $( \pm 12,9)$ anos, submetidos a um teste incremental escalonado em cicloergômetro, 21,05\% da amostra 
foi excluída da análise por apresentar respostas de percepção subjetiva de esforço que não condiziam com o esforço que estavam sendo submetidos. Esta dificuldade foi atribuída a efeitos do envelhecimento, complicações da doença ou ao processo de familiarização com a escala de Borg ${ }^{11}$. Contudo, na prática clínica, tem se utilizado mais testes em esteira para avaliação de parâmetros cardiológicos. Embora o gesto motor seja diferente do aplicado em nossa metodologia (caminhada em relação ao cicloergômetro), foram observadas semelhanças com os resultados de Simões et al. ${ }^{11}$.

Uma possível explicação pode estar relacionada à redução do fluxo sanguíneo cerebral com o processo de envelhecimento ${ }^{13}$, causando declínios em funções cognitivas, que podem afetar a capacidade do idoso em responder ao esforço de forma adequada ${ }^{14}$. No entanto, outro ponto a ser destacado é a influência de uma possível familiarização. Shigematsu et al. ${ }^{22}$ reportaram um coeficiente de autocorrelação somente moderado $(r=0,411)$ entre as respostas de percepção de esforço de dois testes incrementais escalonados semelhantes em indivíduos idosos. Ademais, Lamb et al. ${ }^{23}$ reportaram que a reprodutibilidade das respostas de percepção de esforço podem ser questionadas em testes de esforço progressivo em adultos ativos, indicando uma variação entre as respostas de percepção de esforço em dois testes incrementais escalonados com incrementos de carga semelhantes. Nesse sentido, dada à variação das respostas de percepção de esforço em indivíduos adultos ativos, pode-se aumentar, também, as questões sobre a validade e a reprodutibilidade da percepção de esforço em indivíduos menos ativos e pessoas sem familiarização ao exercício. Contudo, é importante reportar que os autores não estabeleceram um critério de entendimento da escala de PSE, sendo assim, a baixa reprodutibilidade representada pelo coeficiente de autocorrelação pode também estar associada a dificuldades de perceber, relatar e associar o esforço em diferentes intensidades de exercício e não somente ao processo de familiarização.

Por outro lado, grande parte da amostra percebeu, associou e relatou alterações no esforço por meio da escala de PSE. Nesses indivíduos, o percentual da $\mathrm{POT}_{\max }$ e da $\mathrm{FC}_{\max }$ referente aos momentos P13 e P14 não apresentavam diferença significativa comparado ao momento do PCR. Enquanto que, os mesmos parâmetros referentes aos momentos P12 e P15 foram diferentes comparados ao PCR. Ademais, os percentuais da POT${ }_{\max }$ e $\mathrm{FC}_{\text {max, }}$, no momento PLAn, não apresentaram diferença significante quando comparado ao momento P10. Nesse sentido, os resultados do presente estudo indicam que as PSE 13 e 14 na escala de Borg coincidem com o momento do PCR e a PSE 10 coincide com o LAn.

Contudo, em contradição aos nossos resultados, Deruelle et al. ${ }^{17}$ reportaram que a PSE 15 pode ser usada para detectar a intensidade referente ao PCR. Enquanto que, a PSE entre 12-13 pode coincidir com LAn em TE com protocolo escalonado em mulheres e homens idosos treinados. Simões et al. ${ }^{11}$ em sua proposta com diabéticos tipo 2 submetidos a teste incremental em cicloergômetro com protocolo escalonado, reportaram que cargas de trabalho, consumo de oxigênio $\left(\mathrm{VO}_{2}\right)$ e frequência cardíaca $(\mathrm{FC})$ correspon- 
dente as PSE 13 e 14 não apresentaram diferenças significativa em relação aos mesmos parâmetros correspondentes ao limiar de lactato. Além do mais, as cargas de trabalho, $\mathrm{VO}_{2}$ e a $\mathrm{FC}$ correspondentes ao limiar de lactato não apresentaram diferenças em relação ao limiar glicêmico e ventilatório, esse identificado pelo aumento da $\mathrm{VE} / \mathrm{VO}_{2}$ em relação à $\mathrm{VE} / \mathrm{VCO}_{2}$, ou seja, Limiar ventilatório 1 ou LAn ${ }^{17,20}$. Nesse sentido, as possíveis diferenças das respostas de PSE no momento do PCR e do LAn apresentadas entre os estudos de Simões et al. ${ }^{11}$ e Deruelle et al. ${ }^{17}$ comparados ao nosso, podem estar relacionadas ao protocolo utilizado. Revil et al. ${ }^{24}$ sugerem que incrementos pequenos e contínuos de carga, correspondentes ao protocolo de rampa podem modificar a percepção de esforço e tornar a avaliação menos exigente e mais tolerável aos indivíduos. Enquanto que protocolos escalonados trazem uma mudança de PSE por minuto maior do que protocolos de rampa.

O TE com análise ergoespirométrica continua recebendo atenção da comunidade científica para a avaliação da função cardiorrespiratória ${ }^{2,25}$. O protocolo de rampa tem sido considerado um importante instrumento em testes de natureza exaustiva para levar indivíduos de idade avançada ao máximo esforço ${ }^{26}$. Nesse sentido, a PSE pode ser utilizada como um meio de indicar o esforço máximo em avaliações dessa natureza ${ }^{2}$. A American Heart Association ${ }^{9}$ e Cress et al. ${ }^{5}$ consideram uma PSE de pelo menos 18 na escala de Borg como critério para determinar o esforço máximo. No entanto, esse critério é questionado em se tratando de idosos sedentários ${ }^{27}$. Ademais, Revil et al. ${ }^{24}$ reportaram uma PSE média de $16( \pm 2)$ em homens e mulheres de idade avançada submetidos a avaliação de esforço máximo em cicloergômetro com protocolo de rampa. Os resultados do presente estudo revelaram que em mulheres idosas, a PSE de 18 na escala de Borg pode ser um valor elevado, pois somente $27,78 \%$ da amostra apresentaram PSE maior do que 17 na escala de Borg no momento do esforço máximo e o valor médio de PSE nesse momento foi de 17,2( $\pm 1,4)$.

Por conseguinte, destaca-se que os valores apresentados para indicar o esforço máximo foram baseados em populações diferentes, sugerindo que os valores de PSE para indicar o esforço máximo em idosos, precisam ser revistos ou estudados com mais precisão. Ao nosso conhecimento nenhum estudo demonstrou fatores que possam influenciar ou predizer as respostas de PSE em idosos e em testes incrementais com protocolo de rampa. Contudo, Pires et al. ${ }^{28}$ reportaram que em exercícios com cargas constantes em jovens ativos, a noradrenalina apresenta-se como um importante preditor das respostas de percepção de esforço em exercícios de alta intensidade, ou seja, acima do PCR. Nesse sentido, Jensen et al. ${ }^{29}$ demonstraram que indivíduos idosos apresentam menores concentrações de noradrenalina no esforço máximo comparado a indivíduos jovens em exercício dinâmico no cicloergômetro com incrementos escalonados. Ademais, Sachs et al. ${ }^{30}$ reportaram que além de apresentarem menores concentrações de noradrenalina, no esforço máximo em exercícios em cicloergômetro, com incrementos de cargas escalonados, idosos apresentaram, também, respostas de percepção de esforço menores nesse momento comparado a indivíduos jovens. Dessa forma, uma possível 
explicação para as diferenças entre respostas de percepção do esforço de idosos, pode estar relacionada às concentrações de noradrenalina.

É importante ressaltar que apesar de um número considerável de indivíduos não ter conseguido perceber, associar e relatar alterações no esforço em diferentes zonas de intensidade (30,77\%), ainda há necessidade de mais estudos para investigar os mecanismos fisiológicos e cognitivos que influenciam o processamento do esforço em indivíduos idosos. É oportuno destacar, também, algumas limitações do presente estudo, tais como: ausência de medidas metabólicas adicionais para caracterizar o esforço e ausência de uma sessão de familiarização prévia ao TE. Contudo, no ambiente de avaliação clínica, na grande maioria das vezes, não haverá disponibilidade da aplicação de uma sessão de familiarização antes da realização do TE.

\section{CONCLUSÃO}

Por fim, concluímos que indivíduos idosos podem apresentar dificuldades em perceber, associar e relatar alterações no esforço por meio da escala de Borg em TE com incrementos de carga pequenos e contínuos. Sendo assim, recomenda-se cuidado e triagem na utilização da PSE com mulheres idosas. Finalmente, nas idosas que perceberam, associaram e relataram alterações no esforço em diferentes zonas de intensidade as PSE 13 e 14 na escala de Borg coincidem com o momento do PCR e a PSE 10 coincide com o momento do LAn.

\section{REFERÊNCIAS BIBLIOGRÁFICAS}

1. Arnett SW, Laity JH, Agrawal SK, Cress ME. Aerobic reserve and physical functional performance in older adults. Age Ageing 2008;37(4):384-9.

2. Hugget DL, Connely DM, Overend TJ. Maximal Aerobic Capacity Testing of Older Adults: A Critical Review. J Gerontol A Biol Sci Med Sci 2005;60(1):57-66.

3. Nelson ME, Rejeski WJ, Blair SN, Duncan PW, Judge JO, King AC, et al. Physical activity and public health in older adults: recommendation from the American College of Sports Medicine and the American Heart Association. Med Sci Sports Exerc 2007;39(8):1435-45.

4. Meneghelo RS, Araújo CGS, Stein R, Mastrocolla LE, Albuquerque PF, Serra SM, et al/Sociedade Brasileira de Cardiologia. III Diretrizes da Sociedade Brasileira de Cardiologia sobre Teste Ergométrico. Arq Bras Cardiol 2010;95(5 supl. 1):1-26.

5. Cress ME, Meyer M. Maximal voluntary and functional performance levels needed for independence in adults aged 65 to 97 years. Phys Ther 2003;83(1):37-48.

6. Borg GA. Psychophysical bases of perceived exertion. Med Sci Sports Exerc 1982;14(5): 377-81.

7. Hampson DB, St Clair Gibson A, Lambert MI, Noakes TD. The influence of sensory cues on the perceived of exertion during exercise and central regulation of exercise performance. Sports Med 2001;31(13):935-52.

8. Borresen J, Lambert MI. The quantification of training load, the training response and the effect on performance. Sports Med 2009;39(9):779-95.

9. Fletcher GF, Balady GJ, Amsterdam EA, Chaitman B, Eckel R, Fleg J, et al. Exercise standards for testing and training: a statement for healthcare professionals from the American Heart Association. Circulation 2001;104(14):1694-740.

10. Noakes TD. Rating of perceived exertion as a predictior of the duration of exercise that remains until exhaustion. Br J Sports Med 2008;42(7):623-4.

11. Simões HG, Moreira SR, Hiyane WC, Benford RE, Madrid B, Prada FA, et al. Lactate Threshold Prediction by Blood Glucose and Rating of Perceived Exertion in People with Type 2 Diabetes. Percept Mot Skills 2010;111(2):365-78. 
12. Garber CE, Blissmer B, Deschenes MR, Franklin BA, Lamonte MJ, Lee IM, et al. Quantity and Quality of Exercise for developing and Maintaining Cardiorepiratory, Musculoskeletal, and Neuromotor Fitness in Apparently Healthy Adults: Guidance for Prescribing Exercise. Med Sci Sports Exerc 2011;43(7):1344-59.

13. Ogoh S, Ainslie PN. Cerebral blood flow during exercise: mechanisms of regulation. J Appl Physiol 2009;107(5):1370-80.

14. Groslambert A, Mahon AD. Perceived Exertion: influence of age and cognitive development. Sports Med 2006;36(11):911-28.

15. Myers J, Prakash M, Froelicher V, Do D, Partington S, Atwood JE. Exercise capacity and mortality among men referred for exercise testing. N Engl J Med 2002; 346(11):793-801.

16. Smirmaul BPC, Dantas JL, Fontes EB, Okano AH, de Moraes AC. O nível de treinamento não influência a percepção subjetiva de esforço durante um teste incremental. Rer Bras Cineantropom Desempenho Hum 2010;12(3):159-63.

17. Deruelle F, Nourry C, Mucci P, Bart F, Grosbois JM, Lensel G, et al. Optimal exercise intensity in trained elderly men and women. Int J Sports Med 2007;28(7):612-6.

18. Okano AH, Altimari LR, Simões HG, Moraes AC, Nakamura FY, Cyrino ES, et al. Comparação entre limiar anaeróbio determinado por variáveis ventilatórias e pela resposta do lactato sanguíneo em ciclistas. Rev Bras de Med Esporte. 2006;12(1):39-44.

19. Simões HG, Moreira SR, Moffatt RJ, Campbell CSG. Methods to Identify the Anaerobic Threshold for Type-2 Diabetics and Non-Diabetics Subjects. Arq Bras Cardiol 2010;94(1):67-73.

20. Meyer T, Lucía A, Earnest CP, Kindermann W. A conceptual framework for performance diagnosis and training prescription from submaximal gas Exchange parameters: theory and application. Int J Sports Med 2005;26(Suppl 1):S38-48.

21. Pires FO, Noakes TD, Silva AE, Bertuzzi R, Ugrinowitsch C, Lira FS, et al. Cardiopulmonary, blood metabolite and rating of perceived exertion responses to constant exercises performed at different intensities until exhaustion. Br J Sports Med 2011;45(14): 1119-25.

22. Shigematsu R, Ueno LM, Nakagaichi M, Nho H, Tanaka K. Rate of perceived exertion as tool to monitor cycling exercise intensity in older adults. J Aging Phys Act 2004;12(1):3-9.

23. Lamb KL, Eston RG, Corns D. Reliability of ratings of perceived exertion during progressive treadmill exercise. Br J Sports Med 1999;33(5):336-9.

24. Revil SM, Beck KE, Morgan MD. Comparison of the peak exercise response measured by the ramp and 1-min step cycle exercise protocols in patients with exertional dyspnea. Chest 2002;121(4):1099-105.

25. Almeida JA, Boullosa DA, Pardono E, Lima RM, Morais PK, Denadai BS, et al. The Influence of ACE genotype on cardiovascular fitness of moderately active young men. Arq Bras Cardiol 2012;98(4):315-20.

26. Gill TM, DiPietro L, Krumholz HM. Exercise stress testing for older persons starting an exercise program. JAMA 2000;284(20):2591.

27. Church TS, Gill TM, Newman AB, Blair SN, Earnest CP, Pahor M. Maximal fitness testing in sedentary elderly at substantial risk of disability: LIFE-P study experience. J Aging Phys Act 2008;16(4):408-15.

28. Pires FO, Lima-Silva AE, Bertuzzi R, Casarini DH, Kiss MA, Lambert MI, et al. The influence of peripheral afferent signals on the rating of perceived exertion and time to exhaustion during exercise at different intensities. Phychophysiology 2011;48(9):1284-90.

29. Jensen EW, Espersen K, Kanstrup IL, Christensen NJ. Plasma noradrenaline and ageing: effects of smoking habits. Eur J Clin Invest 1996;26(10):839-46.

30. Sachs C, Hamberger B, Kaijser L. Cardiovascular responses and plasma catecholamines in old age. Clin Physiol 1985;5(6):553-65.

\section{Endereço para correspondência}

Denis César Leite Vieira Universidade Católica de Brasília Programa de Pós Graduação em Educação Física e Saúde. Q.S. 07, Lote $01-$ Bloco G. CEP: $71966-700$ - Águas Claras. DF.Brasil.

E-mail: denis.ucb@hotmail.com 